\title{
Aberrant Methylation of Thrombospondin-1 and Its Association with Reduced Expression in Gastric Cardia Adenocarcinoma
}

\author{
Wei Guo, ${ }^{1}$ Zhiming Dong, ${ }^{1}$ Ming He, ${ }^{2}$ Yanli Guo, ${ }^{1}$ Jianwen Guo, ${ }^{3}$ Zhifeng Chen, ${ }^{1}$ \\ Zhibin Yang, ${ }^{1}$ and Gang Kuang ${ }^{1}$ \\ ${ }^{1}$ Department of Laboratory of Pathology, The Fourth Hospital of Hebei Medical University, Shijiazhuang, Hebei 050011, China \\ ${ }^{2}$ Department of Cardiothoracic Surgery, The Fourth Hospital of Hebei Medical University, Shijiazhuang, Hebei 050011, China \\ ${ }^{3}$ Department of Laboratory of Flow Cytometry of Hebei Cancer Institute, The Fourth Hospital of Hebei Medical University, \\ Shijiazhuang, Hebei 050011, China \\ Correspondence should be addressed to Zhiming Dong, dddzzzmmm@yahoo.com.cn
}

Received 27 August 2009; Revised 8 December 2009; Accepted 31 December 2009

Academic Editor: Haodong Xu

Copyright (C) 2010 Wei Guo et al. This is an open access article distributed under the Creative Commons Attribution License, which permits unrestricted use, distribution, and reproduction in any medium, provided the original work is properly cited.

Aim. Investigate the promoter methylation of the Thrombospondin-1 (TSP1) gene in gastric cardia adenocarcinoma (GCA). Methods. MSP approach, immunohistochemistry method, and RT-PCR were used respectively to examine the promoter methylation of TSP1, its protein and mRNA expression in tumors and corresponding normal tissues. The expression and concentration of TGF- $\beta 1$ were examined respectively by immunohistochemistry and ELISA method. The status of T cell immunity was examined by Flow cytometry analysis. Results. TSP1 was methylated in 34/96 (35.4\%) tumor specimens, which was significantly higher than that in corresponding normal tissues $(P<.001)$. Protein and mRNA expression of TSP1 in GCA tumor tissues were reduced significantly and were associated with TSP1 methylation. The protein expression of TGF- $\beta 1$ was significantly higher in tumor tissues $(P<.001)$ and was associated with TNM stage and histological differentiation. The concentration of active and total TGF- $\beta 1$ did not show significant difference between the GCA patients with hypermethylation of TSP1 and without methylation of TSP1 $(P>.05)$. The function of T cell immunity was significantly different between the GCA patients with hypermethylation of TSP1 and without methylation of TSP1. Conclusions. Epigenetic silencing of TSP1 gene by promoter hypermethylation may play an important role in GCA.

\section{Introduction}

Thrombospondin-1 (TSP1) is part of a thrombospondin family which consists of five members. TSP1 and TSP2 are parts of the first subgroup and are trimers; TSP3, TSP4, and TSP5 are pentamers. All thrombospondins display a high degree of homology, but they are differentially expressed in various tissues in order to agree with their distinct promoters, suggesting different functions for each member of the thrombospondin family. TSP1 was first described in 1971 as a high-molecular weight glycoprotein secreted from blood platelets upon thrombin activation [1]. TSP1 is also synthesized and secreted by various types of cells including osteoblasts, fibroblasts, monocytes, macrophages, smooth muscle cells, and a variety of neoplastic cells [2-4]. TSP1 is a multifunctional, matricellular glycoprotein, containing interacting domains for a large variety of adhesive proteins, cell receptors, and enzymes, and it is involved in numerous biological processes, including cell adhesion, migration and proliferation, cell-cell interactions, angiogenesis, tumor cell metastasis, inflammation, atherosclerosis, hemostasis, and thrombosis $[5,6]$.

TSP1 influences cell behavior by interacting with other extracellular matrix components, including latent TGF- $\beta 1$, and with specific cell surface receptors. TSP1 receptors include $\alpha v \beta 3, \alpha 4 \beta 1, \alpha 5 \beta 1$, and $\alpha 3 \beta 1$ integrins; CD36; CD47; low-density lipoprotein receptor-related protein; and heparan sulfate proteoglycans (HSPGs) [7]. TSP1 activates latent transforming growth factor- $\beta$ (TGF- $\beta$ ) and protects it against inactivation through a2-macroglobulin and decorin 
proteoglycan [8]. The activation of TGF- $\beta 1$ is one of the primary mechanisms for regulating the activity of the TGF- $\beta$ signaling pathway. Several TSP1 receptors are expressed in hematopoietic cells and have been implicated in the regulation of immune functions by TSP1. Endogenous TSP1 connects separate cell-surface receptors functionally and regulates T cell adhesion [9]. Prolonged inflammation in CD47-, or TSP1-deficient mice is accompanied by a local deficiency of $\mathrm{T}$ cell apoptosis [10]. Based on global analysis of gene expression in T cells exposed to TSP1, however, a primary effect of TSP1 is to inhibit T cell antigen receptor (TCR) signaling [11]. TSP1 is predominantly a negative regulator of DC and $\mathrm{T}$ cell function while basal SIRPalpha ligation on APC by CD47 enforces tolerance [12]. In contrast, stimulatory effects of TSP1 or CD47-binding peptides derived from TSP1 have also been reported for the activation, infiltration, and clonal expansion of $\mathrm{T}$ cells [13]. These data indicated that TSP1 can both stimulate and inhibit specific signal transduction pathways in T cells and these opposing responses may arise from interactions of TSP1 with two different T cell receptors, $\alpha 4 \beta 1$ and CD47 [7].

The role of TSP1 in cancer progression remains controversial and presents both stimulatory and inhibitory effects [14]. Inhibition of tumor growth by TSP1 is generally attributed to its antiangiogenic activity and several studies have indicated that TSP1 is an inhibitor of angiogenesis [15]. Transition from a resting to a sprouting phenotype and mitogenic activity of cultured endothelial cells was inhibited by TSP1 [16]. Production of TSP1 by breast carcinoma cells can exert an inhibitory effect on tumor progression [17]. Expression of TSP1 inversely correlated with malignant progression in melanoma, lung, and breast carcinoma cell lines [18]. Furthermore, TSP1 may play an important role in antitumor immunity by enhancing recruitment and activation of M1 tumor-associated macrophages, which provides an additional selective pressure for loss of TSP1 expression during tumor progression [19]. However, conflicting results have been obtained [20], and the effects of TSP1 appeared to be specific both for the types of tumor examined and the experimental model used [15]. The exposition of cryptic sites upon conformational changes can partially explain this contradiction and the analysis of TSP1-directed intracellular signaling pathways activated through specific receptors or supramolecular receptors docking systems may be useful to discriminate the precise function of TSP1 in tumor progression [14]. These interactions are complex, and the net effect of TSP1 to enhance or inhibit tumor progression will need to be defined for each tumor type.

It is now increasingly recognized that aberrant hypermethylation of the $\mathrm{CpG}$ island is associated with silencing of tumor-associated genes in various tumors. Promoter hypermethylation of the TSP1 gene has been found in some primary human carcinomas including gastric carcinomas and colorectal cancer [21, 22]. Methylation status of the $\mathrm{CpG}$ island in promoter regions is an important determinant of gene expression. Gastric cardia adenocarcinoma (GCA), which was formerly registered as esophageal cancer or gastric cancer, has been diagnosed independently in very recent years, due to the improvement in early endoscopic screening and pathologic diagnosis. China is a country with high incidence regions of GCA, especially in Taihang mountain of North China. Exogenous factors including nutrition deficiency, unhealthy living habits, consumption of alcohol and tobacco, and pathogenic infections are generally considered as the risk factors for developing GCA in China [23]; however, only a subset of individuals exposed to the above listed exogenous risk factors would develop GCA, suggesting that multiple genetic and epigenetic events may contribute to the occurrence and progression of GCA. To our best knowledge, the methylation status of TSP1 and its effect on TGF- $\beta 1$ in GCA still remain unknown. In the present study, we evaluated the role of methylation of the $5^{\prime}$ CpG island of TSP 1 and its correlation with TSP1 expression both at mRNA and protein levels in Chinese GCA patients; moreover, to determine whether the methylation status of TSP 1 can influence the activation of TGF- $\beta 1$ and $\mathrm{T}$ cell immunity, we compared the concentration of TGF- $\beta 1$ and $\mathrm{T}$ cell immunity in GCA patients with or without hypermethylation of TSP1.

\section{Methods}

2.1. Study Subjects. The cases with GCA were all inpatients for surgical treatment in the Fourth Affiliated Hospital, Hebei Medical University between 2004 and 2007. The patients included 73 males and 23 females, mean age 57.8 years (ranged from 38 to 78 years). Two $\mathrm{ml}$ of venous blood from each subject was drawn in Vacutainer tubes containing EDTA and at the same time two $\mathrm{ml}$ of nenous blood from each subject was drown in tubes without EDTA before the operation. GCA tissues and corresponding adjacent normal tissues were all obtained from operations. These tissues were divided into two parallel parts, one part was frozen and stored at $-80^{\circ} \mathrm{C}$ until RNA was extracted, the other part was formalin-fixed and paraffin-embedded. Histological tumor typing was carried out on the basis of resected specimens in the Department of Pathology of the same hospital. Sample sections were stained in H\&E and were examined by two experienced pathologists. All gastric cardia carcinomas were adenocarcinomas with their epicenters at the gastroesophageal junction, that is, from $1 \mathrm{~cm}$ above until $2 \mathrm{~cm}$ below the junction between the end of the tubular esophagus and the beginning of the saccular stomach [24]. Information on tumor-node-metastasis (TNM) classification was available from hospital recordings and pathological diagnosis, 7 of them were stage I $(7.3 \%), 35$ were stage II $(36.5 \%), 39$ were stage III $(40.6 \%)$, and 15 were stage IV (15.6\%). According to the pathological phases, the cases were classified into 3 groups, $43(44.8 \%)$ of them were well differentiated, 35 (36.4\%) were moderate differentiated, and 18 (18.8\%) were poor differentiated. Venous blood samples with and without EDTA from 30 healthy volunteers during the same period were collected as the controls. The study was approved by the Ethics Committee of Hebei Cancer Institute and informed consent was obtained from all recruited subjects.

2.2. Methylation Analysis of TSP1. Genomic DNA from gastric cardia adenocarcinomas and adjacent nonmalignant 
sections were isolated by manual microdissected method from paraffin-embedded tissue slides using a simplified proteinase $\mathrm{K}$ digestion method. To examine the DNA methylation patterns, we treated genomic DNA with sodium bisulfite, as described previously [25]. In brief, $2 \mu \mathrm{g}$ of DNA were denatured with $2 \mathrm{M} \mathrm{NaOH}$ at $37^{\circ} \mathrm{C}$ for 10 minutes, followed by incubation with $3 \mathrm{M}$ sodium bisulphite (pH5.0). The samples were over layered with mineral oil to cover surface of the aqueous phase, and incubated at $50^{\circ} \mathrm{C}$ for 16 hours. The DNA samples were then desalted through a column of Wizard DNA Clean-up System (Promega, Wisconsin, USA) according to the manufacturer's instructions. The samples were incubated with $3 \mathrm{M} \mathrm{NaOH}$ at room temperature for five minutes, precipitated with $10 \mathrm{M}$ ammonium acetate and $100 \%$ ethanol, washed with $70 \%$ ethanol, and resuspended in $20 \mu \mathrm{l}$ of distilled water.

The methylation status of TSP1 was then determined by methylation-specific polymerase chain reaction (MSP). Bisulfate treatment of genomic DNA converts cytosine to uracil bases but has no effect on methylcytosine. The specific PCR was then used to distinguish between methylated and unmethylated DNA sequences. The primer sequences for the methylated form were $5^{\prime}$-TGC GAG CGT TTT TTT AAA TGC-3' (sense) and 5' ${ }^{\prime}$-TAA ACT CGC AAA CCA ACT CG-3' (antisense) (74 bp), and the primer sequences for the unmethylated form were $5^{\prime}$ - GTT TGG TTG TTG TTT ATT GGT TG-3' (sense) and 5'-CCT AAA CTC ACA AAC CAA CTC A-3' (antisense) (115bp). The PCR condition consisted of one incubation of 10 minutes at $95^{\circ} \mathrm{C}$, followed by 35 cycles of $94^{\circ} \mathrm{C}$ for $30 \mathrm{~s}, 62^{\circ} \mathrm{C}$ for $30 \mathrm{~s}$, and $72^{\circ} \mathrm{C}$ for $30 \mathrm{~s}$, and a final extension at $72^{\circ} \mathrm{C}$ for 10 minutes. PCR products were analyzed on $2 \%$ agarose gels with ethidium bromide and visualized under UV illumination. Genomic DNA, methylated in vitro by CpG methyltransferase (Sss I) following the manufacturer's directions (New England BioLabs, Inc., Beverly, MA), was used as a positive control. Water blank was used as a negative control.

\subsection{Immunohistochemical Staining for TSP1 and TGF- $\beta 1$.} TSP 1 and TGF- $\beta 1$ expressions were determined by immunostaining method, which was performed on parallel histopathological sections from paraffin-embedded tumor section and corresponding adjacent normal tissues. Tissue sections were deparaffinized in xylene, Rehydrated in graded alcohol, and then washed in water. Endogenous peroxidase activity was blocked with $\mathrm{H}_{2} \mathrm{O}_{2}$ treatment. Antigen retrieval was achieved by incubation in $10 \mathrm{mM}$ boiling sodium citrate buffer for $15 \mathrm{~min}$ and nonspecific binding was blocked by treating the sections with $1.5 \%$ horse normal serum for 10 minutes. The slides were sequentially incubated with primary monoclonal anti-TSP1 (A6.1, dilution 1:50, Abcam) and anti-TGF- $\beta 1$ (sc-146, dilution 1:50, Santa Cruz) antibodies at $4^{\circ} \mathrm{C}$ overnight. The Vectastain $\mathrm{ABC}$ Kit was used to obtain the final stain. 3,3'-Diaminobenzidine (Sigma, St Louis, MO) was used as the chromagen. The slides were counterstained with hematoxylin. For a negative control, the primary antibody was replaced with mouse IgG.
Slides with normal gastric mucosa were used as a positive control.

2.4. RT-PCR Analysis of the TSP1 Transcript. RNA was extracted from frozen section tissues by standard methods using Trizol (Invitrogen, USA). cDNA was synthesized using the advantage RT-for-PCR kit (Clontech, Palo Alto, CA) with oligo (dT) priming as recommended in the protocol provided. The GAPDH gene was used as internal control. The primers for TSP1 were $5^{\prime}$-AAA GCG TCT TCA CCA GAG ACC T-3' (sense) and 5'-GCA GAT GGT AAC TGA GTT CTG ACA-3' (antisense) (496 bp). The primers for GAPDH were $5^{\prime}$-CCA TGG AGA AGG CTG GGG-3' (sense), and $5^{\prime}$-CAA AGT TGT CAT GGA TGA CC-3' (antisense) (250 bp). The thermal cycles were $94^{\circ} \mathrm{C}$ for $5 \mathrm{~min}$, followed by 35 cycles of $94^{\circ} \mathrm{C}$ for $60 \mathrm{~s}, 55^{\circ} \mathrm{C}$ for $60 \mathrm{~s}$ and $72^{\circ} \mathrm{C}$ for $60 \mathrm{~s}$, and finally $72^{\circ} \mathrm{C}$ for 10 minutes for extension. The PCR products were separated in $2 \%$ agarose gel in electrophoresis and visualized with ethidium bromide staining.

2.5. TGF- $\beta 1$ ELISA Assay. The blood serum were collected from the venous blood without EDTA of GCA patients and healthy controls. The concentration of TGF- $\beta 1$ was measured with the TGF- $\beta 1$ quantikine enzyme linked immunosorbent assay (ELISA) (DB-100, R\&D Systems, Minneapolis, MN) following the manufacturer's protocol. To measure the concentration of active and latent TGF- $\beta 1$, the serum was divided. The first portion of the serum was activated with hydrochloric acid and the remaining portion of the same media was assessed without any hydrochloric acid treatment. The ELISA assay results were measured using a VERSAmax microplate spectrophotometer (Molecular Devices, Sunnyvale, CA) set at $450 \mathrm{~nm}$.

2.6. Flow Cytometry Analysis. Peripheral blood mononuclear cells (PBMC) were isolated by Ficoll-Paque (SigmaAldrich) density-gradient centrifugation from venous blood containing EDTA of GCA patients and healthy controls. A flow cytometer (Epics-XL II; Beckman Coulter) was used to determine the cell surface expression of CD3, CD4, CD8, $\mathrm{CD}^{+}{ }^{+}$-CD $25^{+}$-Foxp $3^{+}$- regulatory $\mathrm{T}$ (Treg) cells. Mononuclear cells were stained using monoclonal antibodies to CD3, CD4, CD8, CD25 (BD Biosciences, San Jose, CA, USA) and appropriate IgG isotype controls. Costaining of intracellular FOXP3 was performed applying anti-FOXP3 monoclonal antibody PCH101 (eBioscience, San Diego, CA, USA). Samples were analyzed using an FACSCalibur cytometer and CELLQuest software (BD Biosciences).

2.7. Statistical Analysis. Statistical analysis was performed using SPSS11.5 software (SPSS Company, Chicago, Illinois, USA). Results of cell surface molecule and expression, and the level of TGF- $\beta 1$ were expressed as means \pm SD. Chisquare test, Fisher's exact and $t$-tests were used according to the data to assess statistical significance of differences and compare categorical associations. Two-sided tests were used to determine significance, and $P$ values less than .05 were regarded as statistically significant for all statistic tests. 
TABLE 1: Methylation status, immunohistochemical staining characteristics of TSP1, and immunohistochemical staining characteristics of TGF- $\beta 1$ in GCA patients

\begin{tabular}{|c|c|c|c|c|c|c|c|c|c|}
\hline \multirow[t]{2}{*}{ Group } & \multicolumn{2}{|c|}{$\begin{array}{l}\text { Methylation } \\
\text { status of TSP1 }\end{array}$} & \multirow[t]{2}{*}{$P$} & \multicolumn{2}{|c|}{$\begin{array}{c}\text { Protein } \\
\text { expression of TSP1 }\end{array}$} & \multirow[t]{2}{*}{$P$} & \multicolumn{2}{|c|}{$\begin{array}{c}\text { Protein } \\
\text { expression of TGF- } \beta 1\end{array}$} & \multirow[t]{2}{*}{$P$} \\
\hline & $\mathrm{M}$ & $\mathrm{U}$ & & - & + & & - & + & \\
\hline \multicolumn{10}{|l|}{ TNM stage } \\
\hline I & 1 & 6 & & 0 & 7 & & 5 & 2 & \\
\hline II & 9 & 26 & & 7 & 28 & & 20 & 15 & \\
\hline III & 16 & 23 & & 14 & 25 & & 17 & 22 & \\
\hline IV & 8 & 7 & $.036^{\mathrm{a}}$ & 6 & 9 & $.028^{\mathrm{a}}$ & 4 & 11 & $.045^{\mathrm{a}}$ \\
\hline \multicolumn{10}{|c|}{$\begin{array}{l}\text { Pathological } \\
\text { differentiation of } \\
\text { tumor }\end{array}$} \\
\hline Well & 13 & 30 & & 10 & 33 & & 29 & 14 & \\
\hline Moderate & 13 & 22 & & 10 & 25 & & 14 & 21 & \\
\hline Poor & 8 & 10 & $.551^{\mathrm{b}}$ & 7 & 11 & $.463^{\mathrm{b}}$ & 3 & 15 & $.001^{\mathrm{b}}$ \\
\hline
\end{tabular}

${ }^{\mathrm{a}} P$ value of stage III and IV patients against stage I and II patients, ${ }^{\mathrm{b}} P$ value among three differentiation groups.

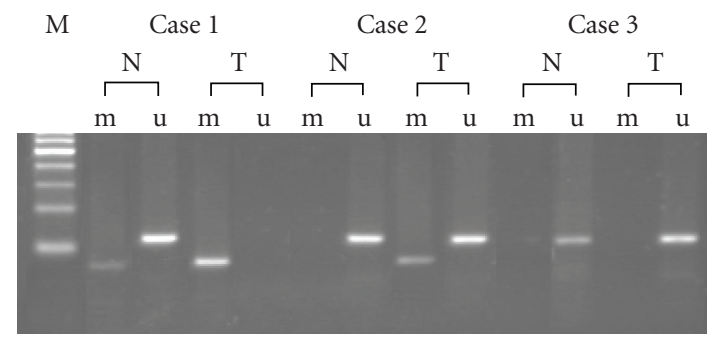

Figure 1: Methylation analysis of TSP1 in tumor tissue (T) and corresponding normal tissue $(\mathrm{N})$. $\mathrm{u}$ : indicates the presence of unmethylated genes; $\mathrm{m}$ : indicates the presence of methylated genes; M: 100 bp DNA marker. Case 1: the tumor is fully methylated, whereas the corresponding normal tissue has a very faint band demonstrating methylation; Case 2: tumor-specific methylation; Case 3: both of tumor and corresponding normal tissues are unmethylated.

\section{Results}

3.1. Methylation Analysis of TSP1 in GCA. The methylation analyses were successfully performed in all tumor and corresponding normal tissues (Figure 1). For 10\% of samples, methylation analyses were repeated for quality control. $34(35.4 \%)$ of 96 GCA tumors displayed TSP1 methylation, while only $3(3.1 \%)$ of paired normal tissues were detected TSP1 methylation. Methylation frequency of TSP1 in tumor tissues was significantly higher than that in paired normal tissues $(P<.001)$. When stratified for TNM, stages frequencies of TSP1 methylation of GCA patients with III and IV stages were significantly higher than GCA patients with I and II stages $\left(\chi^{2}=4.40, P=.04\right)$. No significant association between TSP1 hypermethylation and histological differentiation was found $\left(\chi^{2}=1.19, P=.55\right)$ (Table 1 ).

3.2. Immunostaining of TSP1 Gene. As shown in Table 1, the staining was heterogeneous in 27 tumor tissues (Figure 2).
TABLE 2: Methylation status and mRNA expression of TSP1 in GCA patients.

\begin{tabular}{lcc}
\hline \multirow{2}{*}{ TSP1 mRNA expression } & \multicolumn{2}{c}{ TSP1 methylation status } \\
& Hypermethylation & Unmethylation \\
\hline+ & 6 & 17 \\
- & 22 & 0 \\
\hline$\chi^{2}=26.134, P=.000$. & &
\end{tabular}

Frequency of positive protein expression of TSP1 was 71.9\% (69/96) in tumor tissues, while paired normal tissues all demonstrated positive expression $(P<.001)$. When stratified for TNM stages, Frequencies of TSP1 protein expression of stage III and IV tumor tissues were significantly lower than that in stage I and II tumor tissues $\left(\chi^{2}=4.85, P=.03\right)$. TSP1 protein expression did not correlate with histological differentiation $\left(\chi^{2}=1.54, P=.46\right)$. The tumor tissues without hypermethylation of TSP1 (62 of 96, 64.6\%) all demonstrated positive protein expression of TSP1. A close correlation was noted between TSP1 hypermethylation and the loss of TSP1 protein expression in GCA $(P<.001)$ (Table 1).

3.3. mRNA Expression of TSP1 in GCA. TSP1 mRNA expression was examined by RT-PCR in 45 GCA samples and corresponding normal tissues (Figure 3). TSP1 was expressed in all 45 corresponding normal tissues. The TSP1 mRNA expression levels in GCA tumor tissues were significantly lower than in corresponding normal tissues (OD value: $0.2254 \pm 0.1925$ versus $0.6964 \pm 0.1815, P<.01)$. TSP1 mRNA expression of stage III and IV tumor tissues was significantly lower than that in stage I and II tumor tissues (OD value: $0.1523 \pm 0.0914$ versus $0.2994 \pm 0.1624$, $P<.01) .22 / 28$ tumor samples with hypermethylation of TSP1 did not show TSP1 transcripts. All of the 17 tumor samples without hypermethylation of TSP1 showed positive TSP1 mRNA expression. Overall, there was a significant 


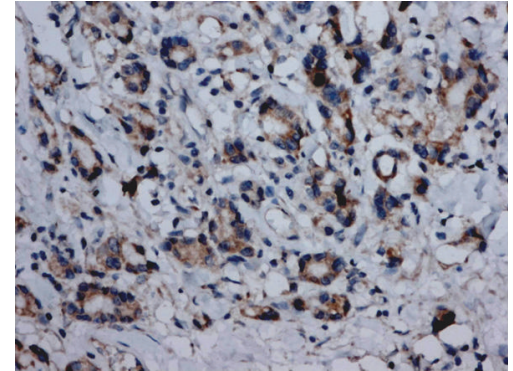

(a) $(\mathrm{SP} \times 200)$

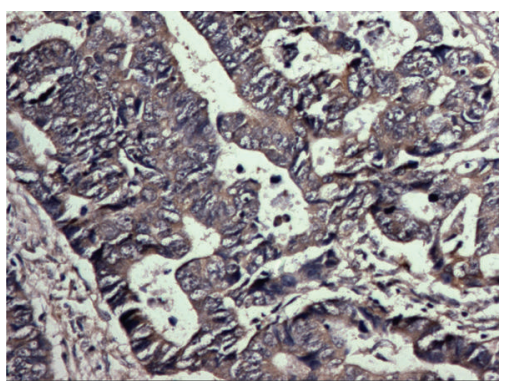

(c) $(\mathrm{SP} \times 200)$

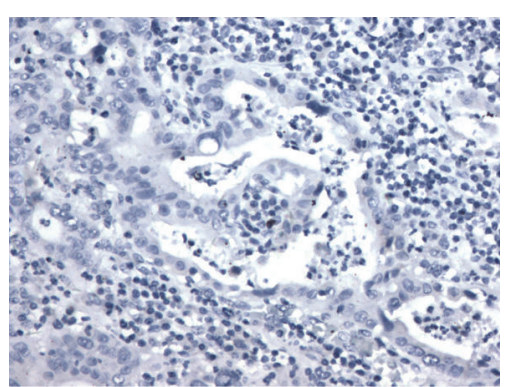

(b) $(\mathrm{SP} \times 200)$

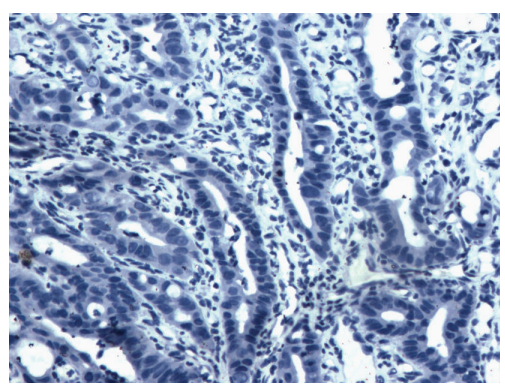

(d) $(\mathrm{SP} \times 200)$

FIGURe 2: Protein expression of TSP1 and TGF- $\beta 1$ in GCA tissues. (a) Positive staining of TSP1, (b) negative staining of TSP1, (c) positive staining of TGF- $\beta 1$, (d) negative staining of TGF- $\beta 1$.

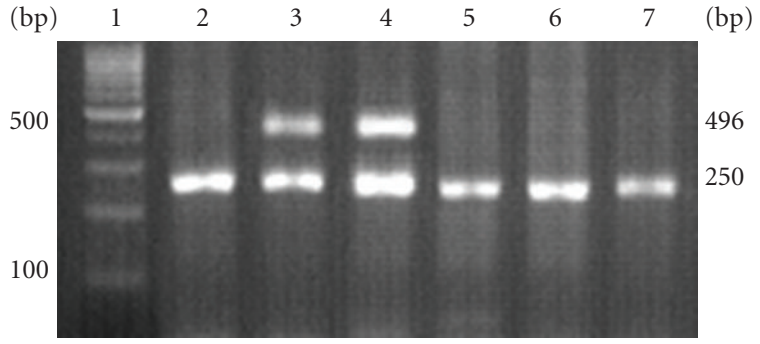

FIGURE 3: RT-PCR analysis of TSP1 in tumor tissues. 1 : 100 bp DNA marker; 2,5,6,7: negative mRNA expression; 3,4: positive mRNA expression.

TABLE 3: Methylation status of TSP1 and protein expression of TGF$\beta 1$ in GCA patients.

\begin{tabular}{lcc}
\hline \multirow{2}{*}{ TGF- $\beta 1$ protein expression } & \multicolumn{2}{c}{ TSP1 methylation status } \\
& Hypermethylation & Unmethylation \\
\hline+ & 24 & 26 \\
- & 10 & 36 \\
\hline
\end{tabular}

$\chi^{2}=7.223, P=.007$.

correlation between TSP1 promoter hypermethylation and loss of TSP1 mRNA expression in GCA samples $(P<.001)$ (Table 2).

3.4. Immunostaining of TGF- $\beta 1$ Gene. The frequency of positive expression of TGF- $\beta 1$ in GCA was $52.1 \%(50 / 96)$, while only $14.6 \%$ (14/96) corresponding normal tissues showed positive protein expression of TGF- $\beta 1(P<.001)$
(Figure 2). When stratified for TNM stages, frequencies of TGF- $\beta 1$ expression of stage III and IV tumor tissues were significantly higher than that in stage I and II tumor tissues $\left(\chi^{2}=4.03, P=.04\right)$. When stratified for histological differentiation, the expression of TGF- $\beta 1$ showed a significant difference among the three groups $\left(\chi^{2}=\right.$ $14.49, P=.001) .24$ tumor tissues with hypermethylation of TSP1 displayed positive protein expression of TGF- $\beta 1$ and there was a significant correlation between TSP1 promoter hypermethylation and positive protein expression of TGF- $\beta 1$ $(P<.01)$ (Table 3$)$.

3.5. The Level of TGF- $\beta 1$ in GCA. ELISA array was used to demonstrate the level of total and activated TGF- $\beta 1$ in GCA patients. We found that the total concentration of TGF- $\beta 1$ in GCA patients was significantly higher than that in healthy controls $(17.25 \pm 6.02 \mu \mathrm{g} / \mathrm{L}$ versus $11.96 \pm$ $3.05 \mu \mathrm{g} / \mathrm{L} ; P<.05)$, while the concentration of activated TGF- $\beta 1$ did not show significant difference between the two groups $(8.26 \pm 5.07 \mu \mathrm{g} / \mathrm{L}$ versus $8.89 \pm 4.17 \mu \mathrm{g} / \mathrm{L} ; P>$ $.05)$. The concentration of total TGF- $\beta 1$ in stage III and IV tumor patients was significantly higher than that in stage I and II tumor patients $(20.85 \pm 5.36 \mu \mathrm{g} / \mathrm{L}$ versus $13.05 \pm$ $4.87 \mu \mathrm{g} / \mathrm{L} ; P<.05)$. Upon providing evidence that whether the aberrant methylation of TSP1 can affect the level of total and active TGF- $\beta 1$, we further assessed the association of TSP1 methylation and the level of TGF- $\beta 1$. We found that the total level of TGF- $\beta 1$ did not show significant difference between the GCA patients with hypermethylation of TSP1 and the GCA patients without hypermethylation of TSP1 $(17.01 \pm 4.12 \mu \mathrm{g} / \mathrm{L}$ versus $17.38 \pm 5.26 \mu \mathrm{g} / \mathrm{L} ; P>.05)$, while the active TGF- $\beta 1$ was lower in the GCA patients 


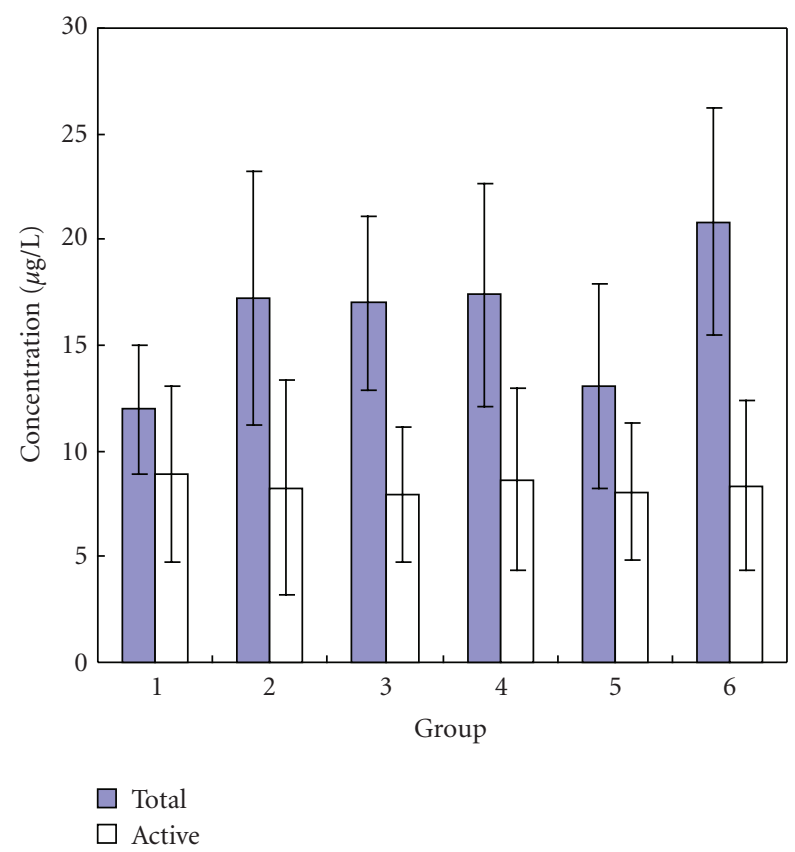

FIGURE 4: The concentration of total and active TGF- $\beta 1$ in different groups. 1: healthy controls, 2: GCA patients, 3: GCA patients with TSP1 methylation, 4: GCA patients without TSP1 methylation, 5: stage I and II GCA patients, 6: stage III and IV GCA patients.

with hypermethylation of TSP1 than that in the GCA patients without hypermethylation of TSP1, but did not show significant difference $(7.96 \pm 3.18 \mu \mathrm{g} / \mathrm{L}$ versus $8.65 \pm$ $4.28 \mu \mathrm{g} / \mathrm{L} ; P>.05$ ) (Figure 4 ).

3.6. TSP1 Methylation and the Association with $T$ Cell Immunity. $\mathrm{CD}^{+}$cells $(55.6 \pm 8.5 \%$ versus $67.7 \pm 7.5 \%$; $P<.05), \mathrm{CD}^{+}$cells $(33.9 \pm 7.6 \%$ versus $45.8 \pm 6.9 \%$; $P<.05)$, and $\mathrm{CD}^{+} / \mathrm{CD}^{+}(0.9 \pm 0.2 \%$ versus $1.6 \pm 0.3 \%$; $P<.05)$ were significantly lower in GCA patients than those in healthy controls, while $\mathrm{CD}^{+}$cells $(38.1 \pm 6.9 \%$ Versus

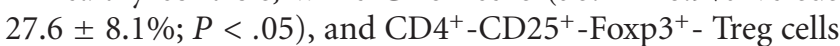
$(7.1 \pm 1.7 \%$ versus $5.2 \pm 0.7 \% ; P<.05)$ were significantly higher in GCA patients than those in healthy controls. When stratified for TNM stages, $\mathrm{CD}^{+}$cells $(40.3 \pm 6.8 \%$ versus $69.2 \pm 7.7 \% ; P<.05), \mathrm{CD} 4^{+}$cells $(27.1 \pm 7.8 \%$ versus 41.4 $\pm 6.9 \% ; P<.05)$, and $\mathrm{CD} 4^{+} / \mathrm{CD}^{+}(0.6 \pm 0.2 \%$ versus $1.2 \pm$ $0.3 \% ; P<.05)$ were significantly lower and $\mathrm{CD}^{+}$cells $(42.2$ $\pm 7.9 \%$ versus $30.7 \pm 7.3 \% ; P<.05), \mathrm{CD}_{4}^{+}-\mathrm{CD} 25^{+}$-Foxp $3^{+}$Treg cells $(8.2 \pm 2.0 \%$ versus $5.9 \pm 1.2 \% ; P<.05)$ were significantly higher in stage III and IV tumor patients than those in stage I and II tumor patients. We also found that $\mathrm{CD}^{+}$cells $(28.2 \pm 8.1 \%$ versus $39.1 \pm 6.9 \% ; P<.05)$, and $\mathrm{CD}^{+} / \mathrm{CD}^{+}(0.8 \pm 0.2 \%$ versus $1.1 \pm 0.3 \% ; P<.05)$ were significantly lower and $\mathrm{CD}^{+}$cells $(40.8 \pm 5.9 \%$ versus $31.9 \pm$ $6.8 \% ; P<.05), \mathrm{CD}^{+}-\mathrm{CD} 25^{+}{ }^{-}$-Foxp $3^{+}$- Treg cells $(7.9 \pm 1.5 \%$ versus $6.2 \pm 1.1 \% ; P<.05)$ were significantly higher in GCA patients with hypermethylation of TSP1 than those in GCA patients without methylation of TSP1, while $\mathrm{CD}^{+}$cells did not show significant difference between the two groups (54.8 $\pm 6.9 \%$ versus $55.9 \pm 7.6 \% ; P>.05$ ) (Figure 5$)$ (Table 4 ).
TABLE 4: The level of TGF- $\beta 1$ in GCA patients $(\mu \mathrm{g} / \mathrm{L})$

\begin{tabular}{|c|c|c|c|c|}
\hline Group & $\begin{array}{l}\text { Level of total } \\
\text { TGF- } \beta 1 \\
(\mathrm{X} \pm \mathrm{S})\end{array}$ & $P$ & $\begin{array}{l}\text { Level of active } \\
\qquad \begin{array}{c}\text { TGF- } \beta 1 \\
(\mathrm{X} \pm \mathrm{S})\end{array}\end{array}$ & $P$ \\
\hline Control & $11.9 \pm 3.1$ & & $8.8 \pm 4.1$ & \\
\hline GCA patients & $17.2 \pm 6.0$ & $.002^{\mathrm{a}}$ & $8.2 \pm 5.0$ & $.253^{\mathrm{a}}$ \\
\hline $\begin{array}{l}\text { Stage I and II } \\
\text { GCA patients }\end{array}$ & $13.0 \pm 4.8$ & & $8.0 \pm 3.2$ & \\
\hline $\begin{array}{l}\text { Stage III and } \\
\text { IV GCA } \\
\text { patients }\end{array}$ & $20.8 \pm 5.3$ & $.001^{\mathrm{b}}$ & $8.3 \pm 4.0$ & $.356^{\mathrm{b}}$ \\
\hline $\begin{array}{l}\text { GCA patients } \\
\text { with } \\
\text { methylation } \\
\text { of TSP1 }\end{array}$ & $17.0 \pm 4.1$ & & $7.9 \pm 3.1$ & \\
\hline $\begin{array}{l}\text { GCA patients } \\
\text { without } \\
\text { methylation } \\
\text { of TSP1 }\end{array}$ & $17.3 \pm 5.2$ & $.423^{\mathrm{c}}$ & $8.6 \pm 4.2$ & $.106^{\mathrm{c}}$ \\
\hline
\end{tabular}

\section{Discussion}

China is a country with high incidence of digestive tract cancer including esophageal carcinoma, gastric cancer, and gastric cardia adenocarcinoma. GCA is highly prevalent in North China, especially in TaiHang mountain of Hebei province. It has been suggested by several epidemiological data that the incidence of GCA is increasing in very recent years [26]. The exact mechanism of the occurrence of GCA remains unclear for the moment. Genetic abnormalities of proto-oncogenes and tumor suppressor genes are wellknown changes that are frequently involved in cancer pathogenesis; however, epigenetic inactivation of certain tumor suppressor genes by aberrant promoter methylation is frequently observed in several cancers and may play a pivotal role in tumorigenesis. TSP1 is one of the genes that has been found to be aberrantly methylated in some colorectal cancers as well as in neuroblastomas, and gastric cancers. It has been suggested that methylated TSP1 may promote tumorigenesis through its effects on angiogenesis [27-29]. In the present study, we found hypermethylation of TSP1 in 35.4\% GCA tumors and its reduced expression at mRNA and protein levels in GCA tumors. In addition, there was a significant concordance between promoter methylation of TSP1 and its lack of protein expression, which indicated that epigenetic silencing of the TSP 1 promoter via hypermethylation may be one of the critical mechanism for inactivation of this gene in GCA.

In our study, we found that in the majority of the cases we examined, TSP1 methylation was tumor specific; however, there were 3 cases $(3.1 \%)$ in which the methylation change was present in both tumor and paired normal tissues from the same patient. Given the high sensitivity of MSP analysis, 

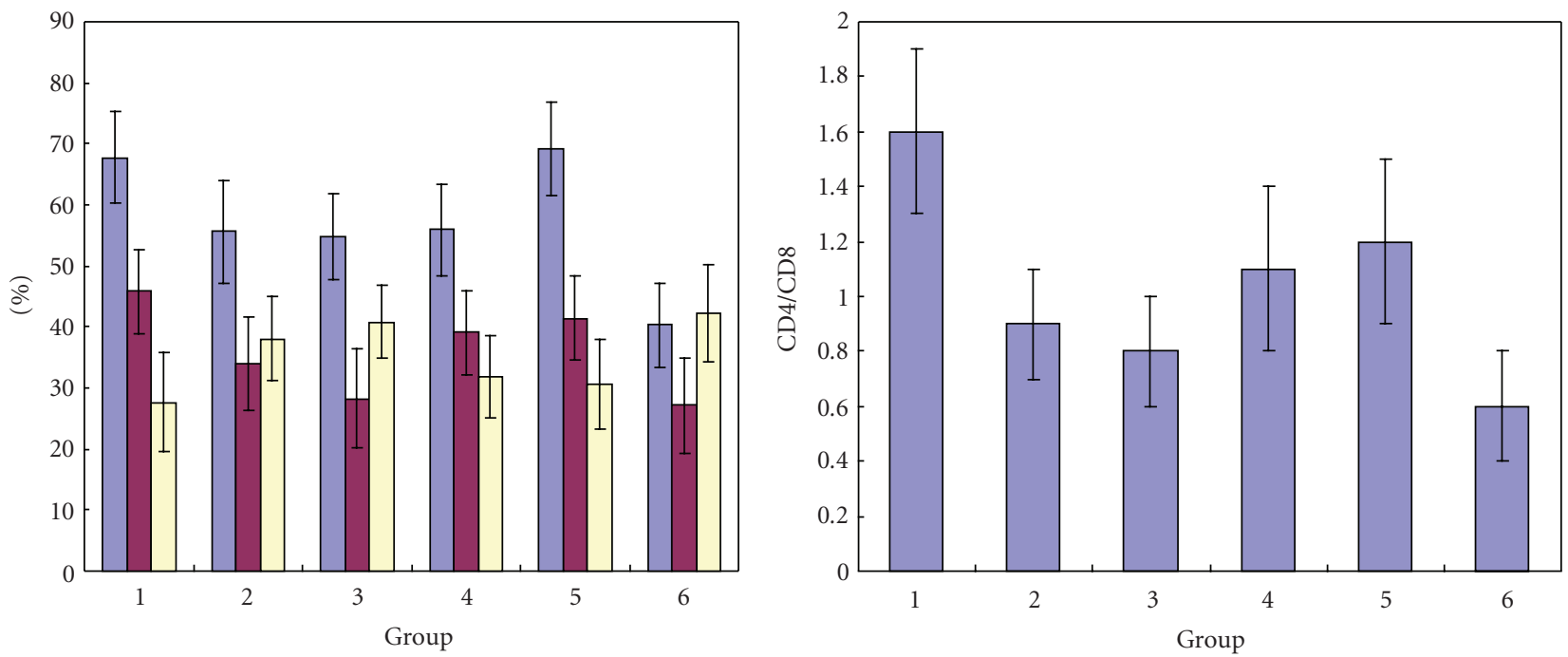

ㄷD3

- CD4

口 CD8

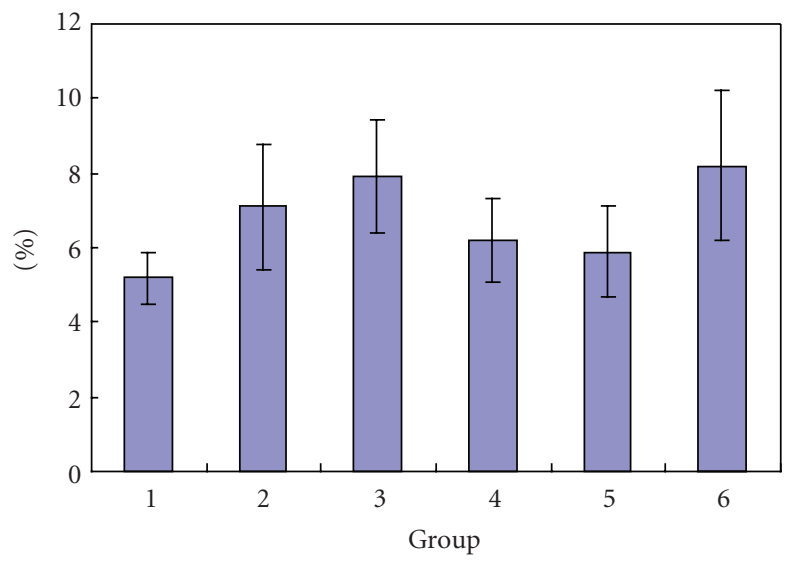

(c)

FIgURE 5: T cell immunity of different groups. (a) CD3, CD4, and CD8 cells in different groups, (b) CD3/CD8 in different groups, (c): $\mathrm{CD}^{+}{ }^{-}$CD $25^{+}$-Foxp $3^{+}$-Treg cells in different groups, 1: healthy controls, 2: GCA patients, 3: GCA patients with TSP1 methylation, 4: GCA patients without TSP1 methylation, 5: stage I and II GCA patients, 6: stage III and IV GCA patients.

it is possible that normal-appearing specimens contained a rare cancer cell that was undetectable by histomorphology; furthermore, the presence of the hypermethylation in corresponding noncancerous tissues may represent the appearance of premalignant lesions. The fact that we only detected methylation in paired normal tissues from patients in whom the corresponding tumor was also methylated is consistent with the hypothesis that the cancer in these individuals arose from a methylated clonal precursor. In a study of neoplastic progression in Barrett's esophagus, hypermethylation of the tumor suppressor gene p16 was detected in pathologically normal-appearing specimens obtained from a patient who later developed dysplasia [30]. Therefore, epigenetic inactivation of tumor-associated genes may be an aberrant and early feature of tumorigenesis.

To our best knowledge, no study of TSP1 promoter methylation and protein expression in GCA has been reported. Recently, there were studies about the correlation of promoter hypermethylation of TSP1 with gastric cancer and colorectal cancer [21,22]; however, the frequency of TSP1 methylation in these tumors and the correlation of TSP1 methylation with histological differentiation and 
tumour staging were different. Oue et al. found promoter hypermethylation of the TSP1 gene in 10 (33\%) of 30 gastric carcinomas and it was associated with mRNA expression levels; however, there was no correlation between TSP1 mRNA expression levels and T grade, $\mathrm{N}$ grade, tumor stage, or histological type [21]. Rojas et al. detected hypermethylation of TSP1 in $21 \%$ colon adenocarcinomas [22]. Here, we demonstrated that TSP1 hypermethylation was correlated with tumor stage in patients with GCA. Types of tumors were different among these studies may be one of the reasons; different proportion of patients according to TNM classification and differentiation of tumors may also lead to the above reported difference. Our results showed that protein expression of TSP1 in tumor tissues was significantly lower than that in paired normal tissues; however, immunohistochemical staining also showed positive staining of TSP1 in some tumor samples with TSP1 methylation. Gene heterogenic methylation or partial methylation may be an important reason. Several studies have reported that partial methylation could cause gene expression in the tumor cells despite promoter hypermethylation [31]. In our studies, we found that the tumor tissues both showed hypermethylation and positive protein expression were all incomplete TSP1 methylation. Furthermore, it has been demonstrated that DNA methylation which suppressed gene expression mainly in transcriptional level and the density of CpG island methylation was related to the suppressed degree of transcription [32]. In our study, we also found positive mRNA expression in some tumor samples with TSP1 methylation. It is partly due to the fact that the extent of promoter methylation was insufficient to suppress TSP1 transcription.

TGF- $\beta$ is a pluripotent cytokine that has a multitude of effects on epithelial cells including the inhibition of proliferation, the duction of apoptosis, and the stimulation of differentiation. It has been demonstrated that TSP1 is required for the activation of secreted TGF- $\beta 1$, and the activation of TGF- $\beta 1$ is one of the primary mechanisms for regulating the activity of the TGF- $\beta$ signaling pathway. Once TGF- $\beta 1$ is activated, it can bind to and activate the TGF- $\beta$ receptor, inducing postreceptor signaling pathways [22]. In this study, we demonstrated that the protein expression of TGF- $\beta 1$ was significantly higher in tumor tissues and was associated with TNM stage and histological differentiation. The total level of TGF- $\beta 1$ was higher in GCA patients and was associated with TNM stage. TGF- $\beta 1$ has the effect of inhibiting the proliferation of human $\mathrm{B}$ and $\mathrm{T}$ cells and is prevalently viewed as an immune suppressive cytokine. The higher protein expression of TGF- $\beta 1$ in GCA patients was consistent with its function. Rojas et al. found that TSP1 inactivation inhibits the activation of secreted TGF- $\beta 1$, and aberrant methylation of TSP 1 can suppress TGF- $\beta$ signaling by impairing the activation of TGF- $\beta 1$ [22]; however, in our study we did not find statistical difference of active TGF- $\beta 1$ level between GCA patients with TSP 1 methylation and without TSP1 methylation. This difference probably due to the fact that our investigation was in vivo while Rojas's was in vitro and as a signaling pathway, TGF- $\beta 1$ activation by TSP 1 cannot be considered as the essential way to generate active TGF- $\beta 1$ in GCA and the activation of TGF- $\beta 1$ may be influenced not only by TSP1 but by other genes as well. It has been found that proteases such as plasmin and matrix metalloproteinases, reactive oxygen species, and the integrins $\alpha \mathrm{v} \beta 6$ or $\alpha \mathrm{v} \beta 8$ can also have the effect of activating TGF- $\beta 1$ $[33,34]$.

The defining feature of a functional immune system is the ability to correctly discern foreign pathogenic antigens from self- or other innocuous antigens and to mount an effective immune response. $\mathrm{T}$ lymphocytes are the key components of the cellular arm of the adaptive immune system. In view of the association of TSP1 and TGF- $\beta 1$, we further evaluated the function of $\mathrm{T}$ cell immunity in GCA patients. We found that CD3, CD4 cells and CD4/CD8 were lower and CD8 were higher in GCA patients and were associated with TNM stage. Foxp3-expressing Treg cells, playing critical roles in suppressing the immune response, were also found higher in GCA patients. We have provided the evidence that GCA patients have the decreased $\mathrm{T}$ cell immunity and with the development of the cancer it has become more serious. We also showed similar tendency between GCA patients with TSP1 methylation and GCA patients without TSP1 methylation. TGF- $\beta$ and Foxp3-expressing Treg cells are critical in maintaining self-tolerance and immune homeostasis. TGF$\beta 1$ suppresses immune responses through at least two ways: inhibiting the function of inflammatory cells and promoting the function of Treg cells. TGF- $\beta 1$ is expressed in Treg at high levels as a cell-surface-bound form [35]. It has been found that TSP1 can promote the generation of human peripheral Treg cells through CD47. CD47 stimulation by $\mathrm{mAb}$ or a TSP1 peptide induced naive or memory CD4+ CD25- T cells to become suppressive. The latter expressed increased amounts of CTLA-4, OX40, GITR, and Foxp3 and inhibited autologous Th0, Th1, and Th2 cells [36]. In our study, Treg cells were higher in GCA patients with hypermethylated TSP1, it partly due to the fact that the proportion of stage III and IV GCA patients (54 of 96, 56.3\%) was higher than stage I and II tumor patients (42 of 96, $43.7 \%$ ); Treg cells and the frequency of TSP1 methylation of stage III and IV GCA patients were also higher than those of stage I and II tumor patients. The stage III and GCA patients in our study both showed lower $\mathrm{T}$ cell immunity function and higher frequency of TSP1 methylation. Further work should be done in a larger cases to detect the exact mechanism.

In summary, Our results suggested that the aberrant methylation of TSP1 is an epigenetic event that silences this gene in gastric cardia adenocarcinoma, and TSP1 may not be the main factor of activating TGF- $\beta 1$ in this cancer. Further work is necessary to elucidate its exact function and interaction with other factors to develop strategies for early diagnosis, prevention, and treatment of gastric cardia adenocarcinoma.

\section{Acknowledgment}

This study was supported by grants from the considerable distinctive subjects foundation of Hebei province. 


\section{References}

[1] N. L. Baenziger, G. N. Brodie, and P. W. Majerus, "A thrombinsensitive protein of human platelet membranes," Proceedings of the National Academy of Sciences of the United States of America, vol. 68, no. 1, pp. 240-243, 1971.

[2] P. G. Robey, M. F. Young, L. W. Fisher, and T. D. McClain, "Thrombospondin is an osteoblast-derived component of mineralized extracellular matrix," Journal of Cell Biology, vol. 108, no. 2, pp. 719-727, 1989.

[3] E. A. Jaffe, J. T. Ruggiero, and D. J. Falcone, "Monocytes and macrophages synthesize and secrete thrombospondin," Blood, vol. 65, no. 1, pp. 79-84, 1985.

[4] R. A. Majack, S. C. Cook, and P. Bornstein, "Platelet-derived growth factor and heparin-like glycosaminoglycans regulate thrombospondin synthesis and deposition in the matrix by smooth muscle cells," Journal of Cell Biology, vol. 101, no. 3, pp. 1059-1070, 1985.

[5] J. C. Adams and J. Lawler, "The thrombospondins," International Journal of Biochemistry and Cell Biology, vol. 36, no. 6, pp. 961-968, 2004.

[6] H. Chen, M. E. Herndon, and J. Lawler, "The cell biology of thrombospondin-1," Matrix Biology, vol. 19, no. 7, pp. 597614,2000

[7] Z. Li, M. J. Calzada, J. M. Sipes, et al., "Interactions of thrombospondins with $\alpha 4 \beta 1$ integrin and CD47 differentially modulate T cell behavior," Journal of Cell Biology, vol. 157, no. 3, pp. 509-519, 2002.

[8] S. Schultz-Cherry and J. E. Murphy-Ullrich, "Thrombospondin causes activation of latent transforming growth factor- $\beta$ secreted by endothelial cells by a novel mechanism," Journal of Cell Biology, vol. 122, no. 4, pp. 923-932, 1993.

[9] S. S. Li, Z. Liu, M. Uzunel, and K.-G. Sundqvist, "Endogenous thrombospondin-1 is a cell-surface ligand for regulation of integrin-dependent T-lymphocyte adhesion," Blood, vol. 108, no. 9, pp. 3112-3120, 2006.

[10] L. Lamy, A. Foussat, E. J. Brown, P. Bornstein, M. Ticchioni, and A. Bernard, "Interactions between CD47 and thrombospondin reduce inflammation," Journal of Immunology, vol. 178, no. 9, pp. 5930-5939, 2007.

[11] Z. Li, L. He, K. E. Wilson, and D. D. Roberts, "Thrombospondin-1 inhibits TCR-mediated T lymphocyte early activation," Journal of Immunology, vol. 166, no. 4, pp. 2427-2436, 2001.

[12] M. Sarfati, G. Fortin, M. Raymond, and S. Susin, "CD47 in the immune response: role of thrombospondin and SIRP-alpha reverse signaling," Current Drug Targets, vol. 9, no. 10, pp. 842850, 2008.

[13] A. N. Vallejo, L. O. Mügge, P. A. Klimiuk, C. M. Weyand, and J. J. Goronzy, "Central role of thrombospondin-1 in the activation and clonal expansion of inflammatory T cells," Journal of Immunology, vol. 164, no. 6, pp. 2947-2954, 2000.

[14] B. Sid, H. Sartelet, G. Bellon, et al., "Thrombospondin 1: a multifunctional protein implicated in the regulation of tumor growth," Critical Reviews in Oncology/Hematology, vol. 49, no. 3, pp. 245-258, 2004.

[15] D. D. Roberts, "Regulation of tumor growth and metastasis by thrombospondin-1," FASEB Journal, vol. 10, no. 10, pp. 11831191, 1996.

[16] A. E. Canfield and A. M. Schor, "Evidence that tenascin and thrombospondin-1 modulate sprouting of endothelial cells," Journal of Cell Science, vol. 108, no. 2, pp. 797-809, 1995.

[17] D. L. Weinstat-Saslow, V. S. Zabrenetzky, K. VanHoutte, W. A. Frazier, D. D. Roberts, and P. S. Steeg, "Transfection of thrombospondin 1 complementary DNA into a human breast carcinoma cell line reduces primary tumor growth, metastatic potential, and angiogenesis," Cancer Research, vol. 54, no. 24, pp. 6504-6511, 1994.

[18] V. Zabrenetzky, C. C. Harris, P. S. Steeg, and D. D. Roberts, "Expression of the extracellular matrix molecule thrombospondin inversely correlates with malignant progression in melanoma, lung and breast carcinoma," International Journal of Cancer, vol. 59, no. 2, pp. 191-195, 1994.

[19] G. Martin-Manso, S. Galli, L. A. Ridnour, M. Tsokos, D. A. Wink, and D. D. Roberts, "Thrombospondin 1 promotes tumor macrophage recruitment and enhances tumor cell cytotoxicity of differentiated U937 cells," Cancer Research, vol. 68, no. 17, pp. 7090-7099, 2008.

[20] V. P. Castle, X. Ou, K. O’Rourke, and V. M. Dixit, "High level thrombospondin 1 expression in two NIH 3T3 cloned lines confers serum- and anchorage-independent growth," Journal of Biological Chemistry, vol. 268, no. 4, pp. 2899-2903, 1993.

[21] N. Oue, S. Matsumura, H. Nakayama, et al., "Reduced expression of the TSP1 gene and its association with promoter hypermethylation in gastric carcinoma," Oncology, vol. 64, no. 4, pp. 423-429, 2003.

[22] A. Rojas, S. Meherem, Y.-H. Kim, et al., "The aberrant methylation of TSP1 suppresses TGF- $\beta 1$ activation in colorectal cancer," International Journal of Cancer, vol. 123, no. 1, pp. 1421, 2008.

[23] Y. Yokokawa, S. Ohta, J. Hou, et al., "Ecological study on the risks of esophageal cancer in Ci-Xian, China: the importance of nutritional status and the use of well water," International Journal of Cancer, vol. 83, no. 5, pp. 620-624, 1999.

[24] J. R. Siewert and H. J. Stein, "Classification of adenocarcinoma of the oesophagogastric junction," British Journal of Surgery, vol. 85, no. 11, pp. 1457-1459, 1998.

[25] J. G. Herman, J. R. Graff, S. Myöhänen, B. D. Nelkin, and S. B. Baylin, "Methylation-specific PCR: a novel PCR assay for methylation status of CpG islands," Proceedings of the National Academy of Sciences of the United States of America, vol. 93, no. 18 , pp. 9821-9826, 1996.

[26] J.-Y. Li, A. B. Ershow, Z.-J. Chen, et al., "A case-control study of cancer of the esophagus and gastric cardia in Linxian," International Journal of Cancer, vol. 43, no. 5, pp. 755-761, 1989.

[27] Q.-W. Yang, S. Liu, Y. Tian, et al., "Methylation-associated silencing of the thrombospondin-1 gene in human neuroblastoma," Cancer Research, vol. 63, no. 19, pp. 6299-6310, 2003.

[28] S. Lee, K. S. Hwang, H. J. Lee, J.-S. Kim, and G. H. Kang, "Aberrant CpG island hypermethylation of multiple genes in colorectal neoplasia," Laboratory Investigation, vol. 84, no. 7, pp. 884-893, 2004.

[29] H. C. Kim, J. C. Kim, S. A. Roh, et al., "Aberrant CpG island methylation in early-onset sporadic gastric carcinoma," Journal of Cancer Research and Clinical Oncology, vol. 131, no. 11, pp. 733-740, 2005.

[30] B. Klump, C.-J. Hsieh, K. Holzmann, M. Gregor, and R. Porschen, "Hypermethylation of the CDKN2/p16 promoter during neoplastic progression in Barrett's esophagus," Gastroenterology, vol. 115, no. 6, pp. 1381-1386, 1998.

[31] S. A. Foster, D. J. Wong, M. T. Barrett, and D. A. Galloway, "Inactivation of p16 in human mammary epithelial cells by CpG island methylation," Molecular and Cellular Biology, vol. 18, no. 4, pp. 1793-1801, 1998.

[32] A. Bird, "Molecular biology. Methylation talk between histones and DNA," Science, vol. 294, no. 5549, pp. 2113-2115, 2001. 
[33] M. O. Li and R. A. Flavell, "TGF- $\beta$ : a master of all T cell trades," Cell, vol. 134, no. 3, pp. 392-404, 2008.

[34] J. P. Annes, J. S. Munger, and D. B. Rifkin, "Making sense of latent TGF $\beta$ activation," Journal of Cell Science, vol. 116, no. 2, pp. 217-224, 2003.

[35] K. Nakamura, A. Kitani, and W. Strober, "Cell contactdependent immunosuppression by $\mathrm{CD}^{4+} \mathrm{CD}^{25+}$ regulatory $\mathrm{T}$ cells is mediated by cell surface-bound transforming growth factor $\beta$," Journal of Experimental Medicine, vol. 194, no. 5, pp. 629-644, 2001.

[36] P. Grimbert, S. Bouguermouh, N. Baba, et al., "Thrombospondin/CD47 interaction: a pathway to generate regulatory $\mathrm{T}$ cells-from human $\mathrm{CD}^{4+} \mathrm{CD}^{25-} \mathrm{T}$ cells in response to inflammation," Journal of Immunology, vol. 177, no. 6, pp. 3534-3541, 2006. 


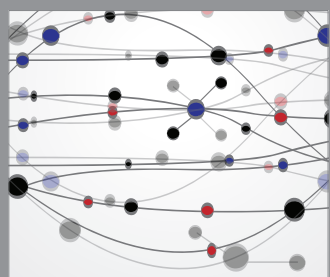

The Scientific World Journal
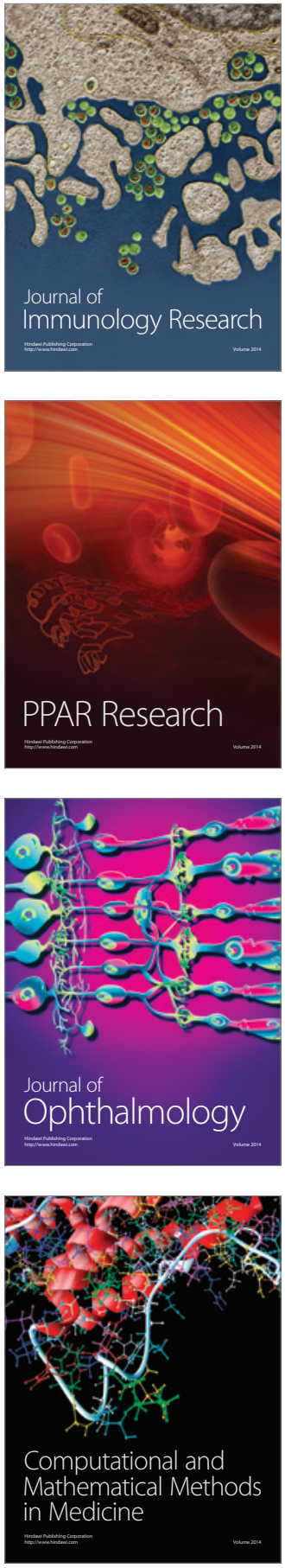

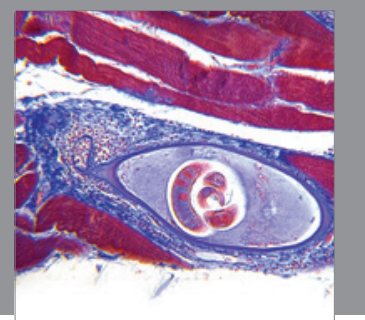

Gastroenterology

Research and Practice
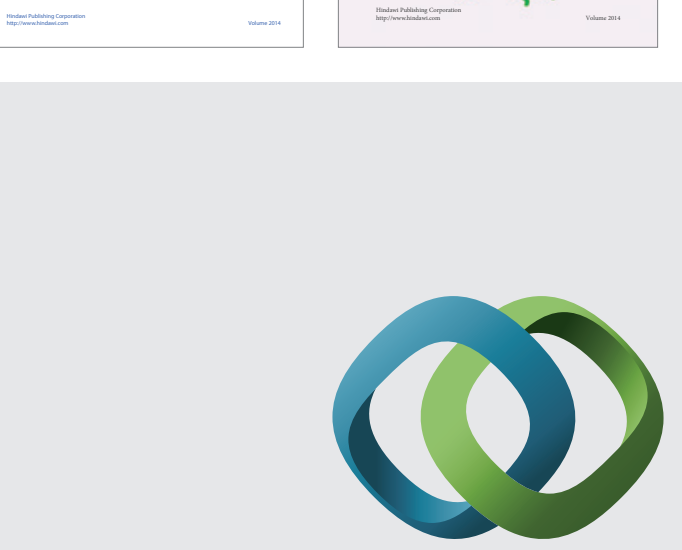

\section{Hindawi}

Submit your manuscripts at

http://www.hindawi.com
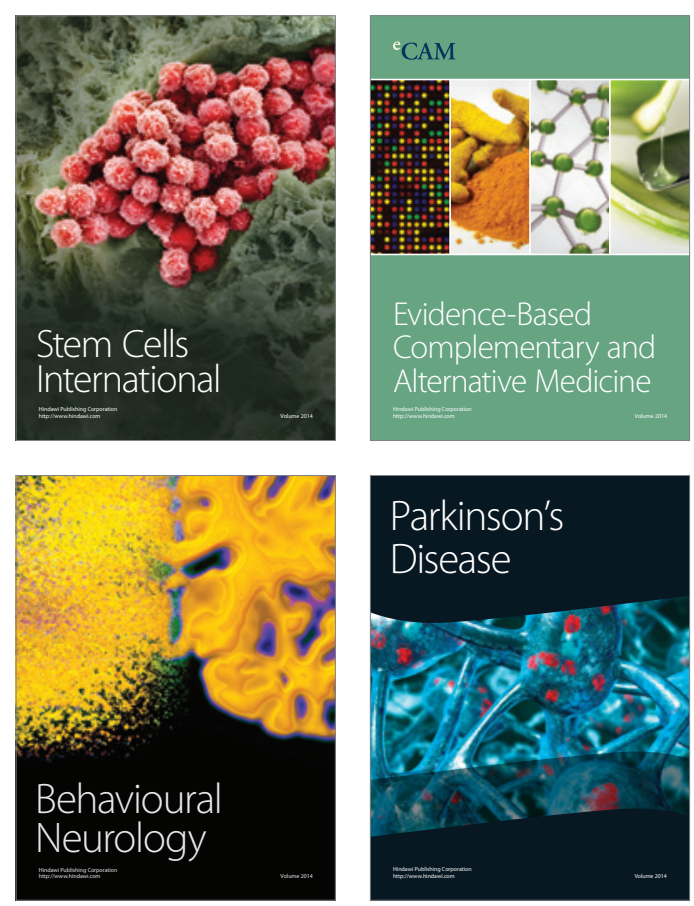

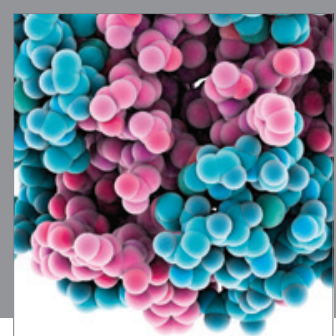

Journal of
Diabetes Research

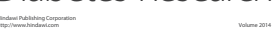

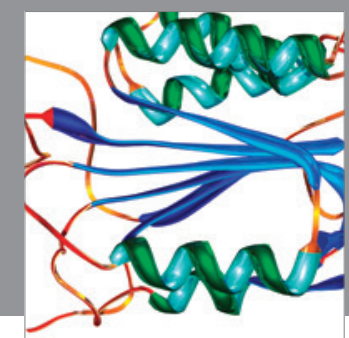

Disease Markers
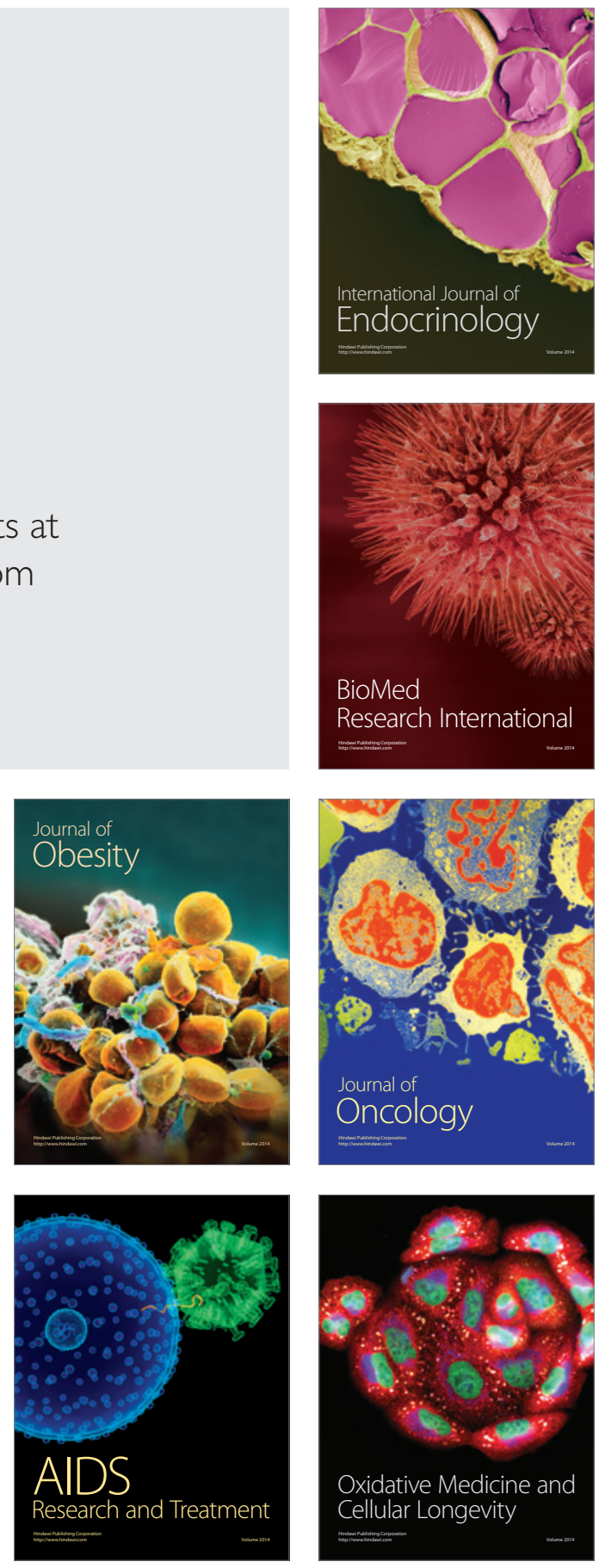